\title{
A Milonga e o Pampa: atravessamentos culturais entre Brasil, Argentina e Uruguai
}

\author{
La Milonga y el Pampa: atravesamientos culturales entre Brasil, \\ Argentina y Uruguay
The Milonga and the Pampa: cultural crossings between Brazil, Argentina and Uruguai

Bruno Blois Nunes ${ }^{1}$

Thiago Silva de Amorim Jesus ${ }^{2}$

\begin{abstract}
Resumo
Este artigo foi idealizado a partir de um seminário realizado na disciplina de Laboratório de Danças Folclóricas do Curso de Dança - Licenciatura da Universidade Federal de Pelotas (UFPel). Este estudo propõe problematizar a Milonga dentro de uma perspectiva histórica e seus desdobramentos na cultura pampeana, mais especificamente nos contextos sul-rio-grandense (Brasil), uruguaio e argentino. Para essa pesquisa foi realizado um levantamento inicial em Plataformas Digitais com o objetivo de obter trabalhos que debatessem a temática proposta. Foi observada uma carência de estudos que abordassem a Milonga, principalmente sob a perspectiva da dança. No âmbito dos materiais encontrados, foi possível perceber a significativa influência do Movimento Tradicionalista Gaúcho (MTG) para a disseminação desta poética pelo Rio Grande do Sul. Por fim, é importante ressaltar a valiosa experiência proporcionada pelo seminário realizado na disciplina de Laboratório de Danças Folclóricas, pois o mesmo possibilitou o estudo de um tema relevante para a discussão de temáticas como cultura, identidade e folclore atentando, neste caso, para as possibilidades poéticas fronteiriças e os atravessamentos culturais na Região do Pampa.
\end{abstract}

Palavras-chave: Milonga; Dança; Pampa; Cultura.

\section{Resumen}

Este artículo fue ideado a partir de un seminario realizado en la disciplina de Laboratorio de Danzas Folclóricas del Curso de Danza - Licenciatura de la Universidad Federal de Pelotas (UFPel). Este estudio propone problematizar a Milonga dentro de una perspectiva histórica y sus desdoblamientos en la cultura pampeana, más específicamente en los contextos sur-rio-grandense (Brasil), uruguayo y argentino. Para esa investigación se realizó un levantamiento inicial en Plataformas Digitales con el objetivo de obtener trabajos que debatieran la temática propuesta. Se observó una carencia de estudios que abordaran a Milonga, principalmente bajo la perspectiva de la danza. En el ámbito de los materiales encontrados, posible percibir la significativa influencia del Movimiento Tradicionalista Gaúcho (MTG) para la diseminación de esta poética por el Río Grande del Sur. Por último, es importante resaltar la valiosa experiencia proporcionada por el seminario realizado en la disciplina de Laboratorio de Danzas Folclóricas, porque el mismo posibilitó el estudio de un tema relevante para la discusión de temáticas como cultura, identidad y folklore atentando, en este caso, hacia las posibilidades poéticas fronterizas y los atravesamientos culturales en la Región del Pampa.

Palabras clave: Milonga; Danza; Pampa; Cultura.

Abstract

This article was conceived from a seminar held in the discipline of Folk Dances Laboratory of the Dance Course - Licenciatura of the Federal University of Pelotas (UFPel). This study proposes to problematize the Milonga within a historical perspective and its unfolding in the Pampas culture, more specifically in the South-Rio-

\footnotetext{
${ }^{1}$ Doutorando em Educação pela UFPel; Pelotas; RS; Brasil; bruno-blois@ @otmail.com

${ }^{2}$ Doutor em Ciências da Linguagem pela UNISUL; Palhoça; SC; Brasil; thiagofolclore@gmail.com
} 
Grandense (Brazil), Uruguayan and Argentine contexts. For this research was carried out an initial survey in Digital Platforms with the objective of obtaining works that debated the proposed theme. There was a lack of studies that addressed Milonga, especially from the perspective of dance. In the context of the materials found, it is possible to notice the significant influence of the Gaucho Traditionist Movement (MTG) for the dissemination of this poetics in Rio Grande do Sul. Finally, it is important to highlight the valuable experience provided by the seminar held in the discipline of Folk Dance, because it allowed the study of a relevant topic for the discussion of themes such as culture, identity and folklore, in this case, considering the poetic possibilities of the border and cultural crossings in the Pampa Region.

Keywords: Milonga; Dance; Pampa; Culture.

\section{Introdução}

Este artigo é resultado de uma investigação idealizada a partir de um seminário realizado na disciplina de Laboratório de Danças Folclóricas do Curso de Dança Licenciatura da Universidade Federal de Pelotas (UFPel). Uma das propostas de avaliação oferecida na disciplina, ministrada pelo professor Dr. Thiago Silva de Amorim Jesus, foi a elaboração de um estudo de uma manifestação folclórica brasileira ou latino-americana em que deveriam ser abordadas questões como: aspectos históricos, geográficos e populacionais dos praticantes além de características estéticas (corporais, coreográficas, musicais e indumentárias) da dança folclórica escolhida, neste caso a Milonga.

Para esse trabalho, os autores pretendem discorrer sobre as questões históricas e os desdobramentos da Milonga na cultura pampeana, mais especificamente nos contextos sulrio-grandense (Brasil), uruguaio e argentino. Dessa forma, serão apresentados no texto algumas informações compartilhadas no seminário da disciplina além de alguns desdobramentos do estudo sobre a Milonga realizados após o processo avaliativo vinculado à disciplina.

Iniciamos elaborando uma breve contextualização acerca da Milonga, enfatizando suas características quanto à música, dança, espaço para a prática de dança e como evento social. A seguir, trataremos da proposta metodológica desse artigo, discutindo alguns resultados considerados relevantes. Por fim, elencamos alguns pontos que destacamos para serem apresentados nas considerações finais.

\section{Referencial Teórico}

Assim como a própria Milonga, que proporciona interrelações culturais entre Brasil, Argentina e Uruguai, esse estudo tem seu suporte teórico construído por autores dos três países. Dentre os autores mencionados durante o texto, três são considerados autores-guias para esse estudo: o uruguaio Lauro Ayestarán, o argentino Carlos Vega e o brasileiro Vitor Ramil. 
A obra intitulada El Folklore Musical Uruguayo (1967), de Lauro Ayestarán, traz uma coletânea de artigos publicados em revistas diversas que foram reunidos ainda em vida pelo autor. Nesse livro, o musicólogo faz um panorama histórico-cultural do folclore uruguaio e entre as diversas manifestações comentadas pelo autor encontramos a Milonga.

Outro autor-guia desse estudo foi Carlos Vega. Em seu livro intitulado Estudíos para los Orígenes del Tango Argentino (2016), o autor tem seu enfoque voltado ao Tango. Contudo, durante a construção do processo histórico do Tango, Vega discorre sobre três manifestações progenitoras do Tango e entre elas está a Milonga.

$\mathrm{O}$ último autor-guia utilizado para essa pesquisa foi Vitor Ramil e o trabalho $A$ Estética do Frio: conferência de Genebra (2009). Essa obra é resultado de uma conferência realizada por Ramil em 2003 quando ele e sua banda passaram por três cidades da Suíça para a realização de alguns shows.

Após essa breve apresentação dos principais teóricos desse estudo, podemos tratar do nosso tema: a Milonga. Pretendemos, nos próximos tópicos, realizar uma contextualização geral da Milonga e seu entendimento como música, dança, espaço de dança e evento social.

\subsection{Milonga: contextualização geral}

A Milonga é uma manifestação cultural muito forte do Rio Grande do Sul, Argentina e Uruguai. Isso ocorre porque muitas vezes o mapa cultural não coincide com o mapa geográfico/político (AYESTARÁN, 1967, p. 22) o que leva a crer que a Milonga consiga borrar os limites geográficos do nosso mapa e seja propagado em diferentes culturas e regiões.

Veremos nesse tópico que o termo Milonga pode ser empregado com mais de um objetivo. Ele pode estar relacionado à música, à dança, ao espaço utilizado para prática de dança e, também, a eventos sociais.

Sua origem é bastante controversa e "há teses para sua origem rio-grandense, sua origem argentina e sua origem uruguaia" (RAMIL, 2009, p. 21). Pelo fato de não podermos determinar de fato o "pai biológico" dessa manifestação, vamos nos ater a algumas referências encontradas para discorrer sobre o assunto.

Por volta de 1870, já é possível perceber a presença da Milonga no folclore uruguaio (AYESTARÁN, 1967, p. 67). Vega (2016, p. 67) pontua não encontrar registros do aparecimento da Milonga, tanto como canto quanto como dança, na Argentina antes de 1880. Entretanto, esse último afirma não ser possível apontar categoricamente sua aparição no mundo, "porque muitas vezes as coisas existem sem que sejam nomeadas por documentos" 
(VEGA, 2016, p. 67, tradução nossa). Isso significa que embora o surgimento da Milonga nos registros históricos date do período mencionado pelo autor, nada disso inviabiliza sua ocorrência em período anterior ao considerado por ambos autores.

Quanto à sua chegada no Rio Grande do Sul, segundo Lessa e Côrtes (apud ALVARES, 2007, p. 13) a Milonga adentra o território brasileiro, mais especificamente o Rio Grande do Sul, pelas regiões fronteiriças indo de Itaqui (divisa com Argentina) até Jaguarão (divisa com o Uruguai). Isso reforça o papel da cultura, em especial da cultura milonguera, como unificador de "povos apartados por montanhas, desertos, rios ou linhas imaginárias" (CARRARO; MACHADO, 2018, p. 78).

De acordo com Ayestarán (1967, p. 67) no final do século XIX a Milonga apresentava três características: 1) canção criolla que se molda com estrofes de quatro, seis, oito e dez versos; 2) usada para "Payada de Contrapunto"; e, 3) utilizada com acompanhamento de baile, ainda em estágio embrionário, de pares que dançavam entrelaçados. Vega (2016, p. 70) reforça que até 1880, na província e subúrbios de Buenos Aires, havia três variedades de Milonga: 1) acompanhamento arpejado que segue determinado padrão rítmico; 2) melodia vocal ou instrumental com frases de quatro, oito ou dez versos em geral e 3) Milonga enquanto dança.

Além das divisões elencadas pelos dois autores referenciados acima, a palavra Milonga também pode significar o espaço de prática de dança assim como as gafieiras representam os locais de prática de samba no Brasil. Atualmente, podemos encontrar três tipos de tango como música e dança: Milonga, Tango e Tango Vals (SEYLER, 2008, p. 108).

Por fim, a Milonga pode ser compreendida como um evento social em que bailarinos se encontram para praticar suas danças. Aqui, não é necessário um espaço físico específico e sua frequência também não segue um calendário rígido.

A seguir passaremos a tratar da Milonga de quatro formas: Milonga enquanto música, dança, espaço de dança e evento social. No próximo tópico, começaremos conceituando a Milonga enquanto música.

\subsection{Milonga enquanto música}

É de extrema complexidade estabelecer divisas sólidas entre o campo e a cidade, ainda mais se tratando de fins do século XIX. Silva acredita que cidade e campo,

Ambos se complementam mesmo contendo significados particulares. Assim, tudo se amplia inclusive na música. E tem sido assim desde o desenvolvimento urbano das 
principais cidades platinas detentoras de uma imensa herança colonial. Desse modo, a milonga desenvolveu-se como uma música da cidade e do campo (2015, p.10).

Ayestarán comenta que inicialmente a Milonga consistia em apenas duas frases (quatro compassos) e depois surgira a Milonga de quatro frases (oito compassos) (1967, p. 71). Nos dias de hoje podemos ver variadas estruturas para a Milonga como as coplas, sextilhas, oitavas e décimas (SCHWARTZ, 2017, p. s/p.).

As Milongas servem de fundo musical para as famosas payadas. ${ }^{3}$ As payadas podem ser realizadas individualmente ou como forma de disputa entre dois payadores. Na payada solo, também conhecida como "compuesto" o payador faz uma improvisação sobre determinado tema, enquanto que na payada de contrapunto ocorre uma disputa entre dois payadores que versam sobre o mesmo tema (AYESTARÁN, 1967, p. 68).

Além das divisões expostas acima, Medeiros e Silva (2014, p. 149-154) comentam que a Milonga possui uma série de variantes e se debruçam sobre três delas: a Milonga pampeana (de andamento lento e, geralmente em tonalidade menor), a Milonga arrabaleira (de andamento mais rápido e, também, em sua maioria executada em tonalidade menor) e a Milonga corraleira (de andamento rápido e raramente executada em tonalidade maior). $\mathrm{O}$ primeiro estilo mencionado pelos autores é aquele bastante presente nas canções de Vitor Ramil, que também pode ser chamado de milonga-canção.

Com todas essas divisões em termos musicais, é possível supor que a milonga enquanto dança também revele diferenças nas formas de bailar. Esse será o assunto do nosso próximo tópico.

\subsection{Milonga enquanto dança}

Outra definição que podemos encontrar sobre Milonga é relativa à dança. Vega diz que, no final do século XIX, a Milonga se trata de uma dança popular das cercanias de Buenos Aires e Montevidéu influenciada pela Habanera cubana e pelo Tango espanhol (2016, p. 73) e que é assimilada pelo tango argentino (HOUAISS; VILLAR, 2001, p. 1924). Durante muito tempo a Habanera cubana, o Tango espanhol (andaluz) e a Milonga se confundiram mutuamente e, repetidas vezes, era comum chamar um desses gêneros com o nome de outro (GOBELLO, 1999, p. 19).

\footnotetext{
${ }^{3}$ Segundo Mendonça (apud Abott, 2015, p. 17) “a payada é uma arte poético-musical em que o artista improvisa uma recitação em rima, cantada e acompanhada por um violão. É uma espécie de gesta, oriunda das manifestações literárias medievais".
} 
Para Vega, é provável que, enquanto dança, a Milonga não tenha surgido antes de 1865, muito embora, o autor reconheça que não há como elaborar essa afirmação de forma categórica pois, como mencionamos anteriormente, "muitas vezes as coisas existem sem serem nomeadas pelos documentos" (2016, p. 67, tradução nossa). Isso revela que, de acordo com os registros encontrados até então, a dança Milonga não é mencionada antes da data relatada por Vega o que não inviabiliza que sua prática tenha sido realizada anteriormente sem o seu devido registro.

De acordo com Chasteen, a Milonga aparece primeiramente como uma forma de dançar um repertório musical já estabelecido nos bailes (2004, p. 19). Isso significa que a Milonga como estilo de dançar surgiu antes de sua música.

A Milonga começa a se desenvolver no final do século XIX, perde prestígio e aparecerá, depois de um longo período, “nas entranhas do tango argentino” (VEGA, 2016, p. 73, tradução nossa). Consequentemente, estruturas da milonga "passam a formar as combinações melódicas da dança" que iria surgir com o nome de Tango (GOBELLO, 1999, p. 19).

Além dessa relação íntima com o Tango, é importante salientar que as formas de se bailar Milonga diferenciavam entre si. No Uruguai, as Milongas nativas eram chamadas de "criollas" enquanto as argentinas se intitulavam "porteñas" (SÁNCHEZ apud VEGA, 2016, p. 68). Essas últimas se caracterizariam por ser bailadas com mais torções de corpo do que aquelas primeiras. Já no Rio Grande do Sul, a Milonga para dançar é "alegre, em tom maior, apropriada ao som forte do acordeom" (RAMIL, 2009, p. 22).

A Milonga tem papel de destaque no cenário gaúcho e atualmente podemos observar três estilos principais de dançá-la: Milonga tangueada dançada com passos de marcha, Milonga vaneirada executada com passos de vaneira ${ }^{4}$ e Milonga riograndense que é bailada no popular 2 e 1 (DANÇAS..., 2010). Abaixo temos uma descrição de como dançar uma Milonga riograndense:

O homem realiza um passo de polca, iniciando com o pé esquerdo, intercalando com um passo de marcha, ou marcação com o pé direito. A dama por sua vez, executa um passo de polca, iniciando com o pé direito, intercalando com um passo de marcha, ou marcação, com o pé esquerdo. Essa milonga tem como característica a realização da pausa após o passo de marcha (SCHWUCHOW apud SIMÕES, 2010, p. 15).

\footnotetext{
4 "Espécie de dança e música muito apreciada no interior, nos bailes de campanha" (OLIVEIRA, 2005, p. 267). É o gênero de dança mais apreciado nos salões gaúchos que pode receber outros nomes de acordo com o andamento da música: vaneirinha (composto por temas mais românticos e de ritmo mais lento), vaneira ou vanera (de andamento intermediário, moderado) e vaneirão (de andamento rápido que aborda aspectos dos usos e costumes do gaúcho) (DANÇAS..., 2010).
} 
Outra forma de utilização do termo milonga é quanto ao espaço de dança. É sobre esses espaços que trataremos no próximo tópico.

\subsection{Milonga enquanto espaço de dança}

Além da Milonga ser compreendida como música e dança, ela também pode significar o espaço físico em que o baile é realizado. Esses espaços servem de encontro para praticantes do Tango (cabe salientar que a Milonga é um dos gêneros incluídos nessa prática) (CAROZZI apud MONDINI BUENO, 2015).

Para um espaço ser identificado como Milonga "tem que acontecer uma reunião de dançadores de Tango de alguma espécie" (SAVIGLIANO, 2000, p. 92). Nesses espaços os convites para bailar se dão através da seguinte forma:

\footnotetext{
Em ambas as milongas, os atores e o público mudam os papéis constantemente. Em algum momento, quem dança na pista senta-se e passa a fazer parte do público, e assim por diante durante todo o dia. A partir do momento em que um dançarino homem, na maioria dos casos - convida seu parceiro para dançar, ele o faz com um gesto chamado na atmosfera do tango como 'cabeceo', fixa seu olhar no outro e faz um sutil movimento da cabeça. Antes deste gesto, o interpelado, se deseja dançar 'concorda com a cabeça', ou se levanta e logo estão na pista; caso contrário, se não quiser dançar, o 'cabeceo' é ignorado, desviando o olhar. O ritual originou-se em Buenos Aires e é praticado apenas em algumas províncias do país e em alguns países (QÜESTA, 2017, p. 82, tradução nossa).
}

Nesses espaços são executados o que se chamam de tandas (uma sequência de três a quatro canções do mesmo estilo) e entre as tandas é executada uma música chamada de "cortina" que indica que os bailarinos podem voltar aos seus lugares e convidar outras pessoas para bailar (HATCHUEL, 2012, p. 69). Atualmente, as orquestras ao vivo foram substituídas por DJs e pouco lugares tem mais de uma pista de dança (SAVIGLIANO, 2000, p. 101).

Além de espaço físico para a prática de Tango, uma última definição de Milonga é relacionada à ideia de evento social. A seguir, vamos abordar essa questão de forma mais detalhada.

\subsection{Milonga enquanto evento social}

A última definição de Milonga proposta por esse trabalho é o emprego de seu termo como evento social. Aqui o foco não reside nos espaços físicos que abrem suas portas para os 
praticantes de dança, mas sim, nos encontros e reuniões de pessoas que tem como objetivo comum dançar.

Um detalhe importante de salientar é que as Milongas, enquanto eventos sociais, não têm calendário e nem lugar pré-definido: podem ser anuais, diárias ou esporádicas como também em um salão de danças, em uma casa particular ou até mesmo nas ruas (SAVIGLIANO, 2000, p. 92). Além disso, o comentário de Savigliano ajuda a ampliar a compreensão de Milonga não se restringindo apenas aos espaços físicos para a prática de dança e considerando também as reuniões/encontros realizados em locais diversos como outra forma de definirmos a palavra Milonga.

Se no tópico anterior, referente à Milonga enquanto espaço de dança, podíamos compará-la com as gafieiras de Samba, no caso da Milonga enquanto evento social, podemos compará-las com as reuniões de samba realizadas para o pessoal tocar, dançar, comer, beber e praticar todos rituais presentes nesse tipo de evento.

Após esse aprofundamento teórico acerca da Milonga, abordaremos as questões relativas à metodologia desse estudo.

\section{Metodologia}

A metodologia desse artigo foi desenvolvida em duas partes: na primeira, através de um levantamento realizado no Google Acadêmico entre os meses de abril e maio de 2018, foi elaborado um pequeno material teórico para apresentação no seminário da disciplina Laboratório de Danças Folclóricas; a segunda parte contou com uma nova pesquisa, realizada no mesmo local em outubro de 2018, afim de levantar documentos que pudessem complementar esse artigo.

O objetivo desse levantamento era pesquisar trabalhos que discutissem a Milonga, sob diferentes aspectos. No primeiro momento, foi feito um levantamento com a palavra-chave "milonga" para tentar extrair um panorama geral do tema, já na segunda etapa foram elaboradas buscas mais avançadas com mais de uma palavra-chave como por exemplo: "milonga" AND "dança” e "milonga" AND “música".

\section{Resultados e discussões}

Primeiramente, é importante ressaltar, a enorme carência de estudos sobre a Milonga. Muitos dos trabalhos encontrados sobre Milonga tinham como temática principal o Tango,

\footnotetext{
${ }^{5} \mathrm{O}$ termo "AND" foi digitado em letras maiúsculas para identificar que foi utilizado o operador booleano AND durante o levantamento de trabalhos nas plataformas digitais.
} 
como por exemplo Estudíos para los Orígenes del Tango Argentino (2016) de Carlos Veja, ou tratavam de variadas manifestações folclóricas na mesma obra, que é o caso de El Folklore Musical Uruguayo (1967) de Lauro Ayestarán.

Um fator que com certeza ajudou na propagação da Milonga foi o Movimento Tradicionalista Gaúcho - MTG. O DVD Danças Gaúchas de Salão apresenta variados estilos de dança praticados nos Centros de Tradições Gaúchas $(\mathrm{CTG})^{6}$ pelo Brasil (e mesmo fora dele) e a Milonga é uma dessas danças ensinadas nesses locais que prezam pela manutenção das tradições da cultura gaúcha.

O fator geográfico também é importante no percurso histórico da Milonga. O Pampa é uma região partilhada por Uruguai, Argentina e Rio Grande do Sul, que serviu de propagadora da milonga entre os três países (SILVA, 2015) e possibilitou a formação de um novo espaço demarcado culturalmente e que não se encontra nos limites geográficos de nossos mapas-múndi tradicionais. Talvez isso se dê pelo fato de que toda fronteira "é barreira e, ao mesmo tempo, o local de comunicação e da troca" (MORIN, 2008, p. 252).

\section{Considerações Finais}

A Milonga pode ser concebida como música, dança, espaço para prática de dança e evento social. Tantos nos espaços físicos, quanto nas reuniões, a Milonga é um dos gêneros praticados pelos dançarinos.

De acordo com registros encontrados, a Milonga é praticada desde a segunda metade do século XIX. Começou como forma de dança para depois passar a fazer parte do repertório de canções denominadas de Milongas.

Tanto na Argentina quanto no Uruguai, é possível identificar uma relação da Milonga muito próxima ao Tango tanto em relação à música como em relação à dança. Já no território do Brasil, é inegável sua forte presença no estado do Rio Grande do Sul, prioritariamente, além de outros estados brasileiros em que os costumes e tradições gaúchas são difundidos.

Dado a enorme carência de estudos acerca dessa temática, consideramos ser muito importante a realização de futuras pesquisas sobre a milonga. Quanto a esse estudo, esperamos que essas poucas páginas tenham oferecido um panorama geral sobre a Milonga e instigue novas pesquisas sobre o tema.

\section{Referências}

\footnotetext{
6 Organizações sem fins lucrativos que buscam propagar a tradição e folclore gaúcho como forma de perpetuação desses costumes.
} 
ABOTT, Milena de Oliveira. Payador, Pampa e Guitarra: tempo, espaço e ecos de uma cultura. 2015. 118f. Dissertação (Mestrado em Letras), Faculdade de Letras, Universidade Federal de Pelotas, Pelotas, 2015. Disponível em: $<$ http://repositorio.ufpel.edu.br/bitstream/ri/2737/5/Payador\%2c\%20pampa\%20e\%20guitarra. pdf $>$. Acesso em: 07 mai. 2018.

ALVARES, Felipe Batistella. Milonga, chamamé, chimarrita e vaneira: origens, inserção no Rio Grande do Sul e os princípios de execução ao contrabaixo. 2007. 35p. Monografia (Licenciatura em Música), Faculdade de Música, Universidade Federal de Santa Maria, Santa Maria, 2007. Disponível em: <http://docplayer.com.br/26568264-Milonga-chamamechimarrita-e-vaneira-origens-insercao-no-rio-grande-do-sul-e-os-principios-de-execucao-aocontrabaixo.html>. Acesso em: 13 out. 2018.

AYESTARÁN, Lauro. El folklore musical uruguayo. Montevideo: Arca, 1967.

CARRARO, Ghadyego; MACHADO, Jeremias. Entre acordes e versos: da identidade fronteiriça aos aspectos históricos e estruturais da milonga. RIHGRGS, Porto Alegre, n.154, p.77-88, jul. 2018. Disponível em:

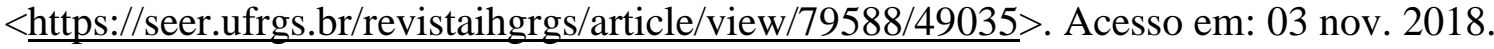

CHASTEEN, John Charles. National Rhythms, African Roots: the deep history of Latin American Popular Dance. Albuquerque: University of New Mexico, 2004.

DANÇAS gaúchas de salão. Instrutor: José Roberto Bertol. Financiamento: Fundo ProCultura - Prefeitura de Caxias do Sul. Realização: Absoluta. Apoio Técnico: MTG Rio Grande do Sul. Caxias do Sul: ACIT, 2010, 1 DVD (127 min), son., col.

GOBELLO, José. Breve história crítica del Tango. Buenos Aires: Corregidor, 1999.

HATCHUEL, Françoise. El tango argentino, entre escenografía pública y sentido interior. In: SIMPÓSIO INTERNACIONAL DE CORPUS, 3, 2010, Lima. Anais... Lima, 2012. p. 67-74. Disponível em: <http://www.uca.edu.sv/facultad/clases/chn/m100136/documentos/Versiondigital-Libro-Corpus-opc-23-de-agosto-1(2).pdf >. Acesso em: 04 nov. 2018.

MEDEIROS, Daniel Ribeiro; SILVA, Danilo Kuhn da. Ares de milonga: apontamentos sobre elementos característicos como bases para performance. DAPesquisa, Florianópolis, v.9, n.11, p. 144-168, 2014. Disponível em: <http://www.revistas.udesc.br/index.php/dapesquisa/article/view/8174>. Acesso em: 29 out. 2018.

MILONGA. In: HOUAISS, A.; VILLAR, M. de S. Dicionário Houaiss da língua portuguesa. Rio de Janeiro: Objetiva, 2001. p. 1924.

MONDINI BUENO, Rafael. Comme il faut: os códigos nas milongas relajadas em Buenos Aires. 2014. 165p. Monografia (Graduação em Ciências Sociais), Faculdade de Ciências Sociais, Universidade Federal de Santa Catarina, Florianópolis, 2015. Disponível em: <https://repositorio.ufsc.br/handle/123456789/128345>. Acesso em: 14 set. 2017.

MORIN, Edgar. $O$ método 2: a vida da vida. Tradução: Marina Lobo. Porto Alegre: Sulina, 2005 . 
OLIVEIRA, Alberto Juvenal de. Dicionário gaúcho: termos, expressões, adágios, ditados e outras barbaridades. 3. ed. Porto Alegre: AGE, 2005.

PAMPA. In: HOUAISS, A.; VILLAR, M. de S. Dicionário Houaiss da língua portuguesa. Rio de Janeiro: Objetiva, 2001. p. 2114.

QÜESTA, Fernanda Lourdes. La comunicación en el tango-danza. Dos casos en la ciudad de Córdoba: Milonga Plaza San Martín y Milonga La Triunfal. 2017. Monografia (Graduação em Ciências da Comunicação), Facultad de Ciencias de la Comunicación, Universidad Nacional de Córdoba, Córdoba-ARG, 2017. Disponível em: <https://rdu.unc.edu.ar/handle/11086/5829>. Acesso em: 12 dez. 2017.

RAMIL, Vitor. A Estética do Frio: conferência de Genebra. Pelotas: Satolep Livros, 2009. Disponível em: $\quad$ http://www.vitorramil.com.br/textos/Vitor_Ramil_A_Estetica_do_Frio.pdf $>$. Acesso em: 27 abr. 2017.

SAVIGLIANO, Marta E. Corpos noturnos, identidades embaçadas, projetos anômalos: seguindo os passos de Cortázar nas milongas de Buenos Aires. Cadernos Pagu, Campinas, n.14, p.87-127, 2000. Disponível em: <https://periodicos.sbu.unicamp.br/ojs/index.php/cadpagu/article/view/8635343/3142>.

Acesso em: 25 nov. 2018.

SCHWARTZ, Jorge (Org.). Borges Babilônico: uma enciclopédia. São Paulo: Companhia das Letras, 2017.

SEYLER, Elizabeth M. Revealing the African Roots of Argentine Tango. Dance Chronicle, London, v.31, n.1, p.104-112, feb. 2008. Disponível em: $<$ https://www.jstor.org/stable/25598145?seq=1\#page_scan tab_contents $>$. Acesso em: 16 jun. 2018.

SILVA, Jeremyas Machado. As milongas e as narrativas na região do Pampa. Estudios Históricos, Rivera-UY, n.15, p. 01-13, dic. 2015. Disponível em: <http://www.estudioshistoricos.org/15/eh\%201508.pdf>. Acesso em: 14 maio 2018.

SIMÕES, Marcelo Brugnara. Passo 2 e 1 no contexto de um baile na cidade de Porto Alegre. 2010. 27p. Monografia (Graduação em Educação Física), Faculdade de Educação Física, Universidade Federal do Rio Grande do Sul, Porto Alegre, 2010. Disponível em: $<$ https://www.lume.ufrgs.br/bitstream/handle/10183/24896/000750028.pdf?sequence=1 >. Acesso em: 30 out. 2018.

VEGA, Carlos. Estudios para los orígenes del tango argentino. 2. ed. Buenos Aires: Universidad Católica Argentina, 2016. 